\title{
TRADE RELATIONS BETWEEN BELGIUM AND ZIMBABWE
}

\author{
Bogdan VAN DONINCK \\ Science Policy Office of Belgium \\ Wetenschapsstraat, 8 \\ 1040 Brussel
}

Several developments within Zimbabwe are encouraging for taking up trade relations with this country:

- the positive growth of the GNP, fluctuating from year to year, but resulting in an average growth of $4 \%$ since independence, whereas the population growth reaches $3 \%$ per year;

- after an increase, there has been a successful effort to reduce the debt service rate, which has been brought down from $35 \%$ in 1988 to $20 \%$ in 1989 ;

- Zimbabwe has, as already has been stressed by several speakers today, a diversified economy and has embarked on a programme of further industrialization;

- within the SADCC, Zimbabwe holds a key position both geographically and in the sense that it has the most developed industry of all the member states.

There are of course also some constraints or limitations on the possibilities of trade with Zimbabwe: 
- Zimbabwe is producing a large number of products, and especially the potential market for consumer items is limited;

- the way import allocations are distributed may discourage some foreign companies, as the procedures are time-consuming and not always very transparent;

- companies prospecting the market, feel uncertain about the priorities set by the government and don't see clear about the way the priorities are put into practice by the different departments involved in international trade;

- sometimes there are conflicting signals between the political statements by the government and the concrete policies followed. Just one example: foreign investment is officially being encouraged, but only recently an investment code has been published;

- Zimbabwe has a tradition of exporting certain goods, such as tobacco, maize and minerals and the business partners know the country and its products. But especially for the exports of non-traditional products, training is needed in such fields as quality control, marketing, financing mechanisms etc. The international market for products such as fruits, vegetables, flowers and also for the semi-finished products Zimbabwe wants to sell, is highly competitive and Zimbabwe must make an effort to meet the requirements not only in terms of price, but also in terms of quality, packaging and delivery time.

If one takes into consideration the industrialisation of Zimbabwe and its place within the SADCC, emphasis should be placed on the exports to Zimbabwe of products in the field of capital goods, i.e. the supply of goods and services, going from spare parts and control equipment to complete lines, that would help Zimbabwe to build up its own industry. Certain fields of industry are certainly of interest to Belgian suppliers, and I am especially thinking of equipment and technology for water supply and irrigation, transport, food processing and the building materials industry. In these fields, there is a complementarity between Zimbabwean needs and Belgian possibilities.

One should not only consider the possibility of selling these goods to Zimbabwe, but also study the possibility of cooperating with Zimbabwe for local production, not only for the Zimbabwean market, but also for the SADCC and even for the PTA market. As you know, Zimbabwe is already selling to these markets and has even competed with Belgian and other European companies, e.g. for the supply of railway wagons to PTA countries. 
A decision to invest should be carefully prepared and one has to ask in which way both governments, i.e. the Belgian and the Zimbabwean government, could assist during this process. I am thinking of support to feasibility studies, but also of initiatives in the field of investment guarantee, state-to-state loans etc. It is not only necessary that interesting conditions for foreign investment exist, but also that the market is made more transparent. Potential foreign investors would certainly be encouraged if they know that they get support from both sides in treating their case seriously and within reasonable time limits. The simplification of the investment procedures was a step in that direction.

The governments should also assist smaller companies, who don't have the possibility to prospect the market on their own in the way TNCs can do. When I am talking about smaller companies, I am thinking not only of Belgian companies that are specialised in certain fields, but also of Zimbabwean companies that are potential suppliers to the Belgian market, but don't know the needs, neither the rules and regulations.

Especially if one wants to diversify the trade relations between both countries, small and medium-sized enterprises should not be forgotten. In this respect, I would like to mention that also Belgian procedures and regulations, e.g. from Delcredere or from BADC, should also be more clear to the small and medium-size companies, and not only to some companies who have the possibility to maintain practically daily contacts with these institutions or have the possibility to participate systematically in trade missions. I am convinced that both in Belgium and in Zimbabwe there are companies that are potential partners, but don't have the possibility to meet and get acquainted.

These are not the only possibilities nor problems in trade with Zimbabwe. A certain degree of creativity will certainly be required from the banks as well as from the government, if it comes to setting up special financing arrangements, not only in the form of mixed credits, but also in the form of financing or investment in joint ventures with Zimbabwean companies that intend to sell on other markets in the region.

It is of course not possible to discuss concrete projects, but I wanted to draw your attention to the possibilities in investment and in cooperation between small and medium-sized enterprises and to the role that the governments can play in these fields. 